\title{
Management of self-inflicted oral organophosphate poisoning in adolescence - a case report
}

\author{
Sattoju Nithish ${ }^{1}$, Jagini Shiva Prasad ${ }^{2}$, Aakaram Sujala ${ }^{3}$, Endla Jagadish Kumar ${ }^{3}$ \\ From ${ }^{1}$ Duty Medical Officer, ${ }^{2}$ Consultant General Physician, Internal Medicine, Medisys Hospitals, ${ }^{3}$ Assistant Professor, Department of Pharm. D, \\ Chilkur Balaji College of Pharmacy, Hyderabad, Telangana, India
}

\begin{abstract}
Organophosphate (OP) poisoning is more common in developing countries such as India. Here, we report a case of self-inflicted oral OP poisoning (monocrotophos) by an adolescent male patient who presented to the emergency department of a tertiary care hospital with tachycardia and frothing without seizure episode (non-linear presentation in OP poisoning). Based on the evidence of consumption of OP compound, the management of the patient went as planned and guarded with i.v. administration of pralidoxime and atropine. Gastric lavage was done soon after the patient came to the hospital and was admitted to the Intensive care unit for 5 days and in the general ward for the next $24 \mathrm{~h}$. The patient was discharged from the hospital in a hemodynamically stable state after 6 days of hospital stay by managing the cardiac, muscarinic, and nervous system events as detailed in this case report.
\end{abstract}

Key words: Acetylcholinesterase, Atropine, Gastric lavage, Organophosphate poisoning, Pralidoxime

$\mathrm{O}$ rganophosphorus (OP) self-poisoning is an important clinical problem in developing countries. An estimate of 200,000 people per year died due to OP self-poisoning with a fatality rate of $>15 \%$. OP inhibits acetylcholinesterase (Ach) enzyme at nerve synapse and butyrylcholinesterase on the red cell membrane, of which inhibition of Ach results in the clinical presentation [1]. Inhibition of Ach results in acetylcholine accumulation and overstimulation of Ach receptors in the synapses of the autonomous nervous system, central nervous system (CNS), and neuromuscular junction. Table 1 provides the clinical presentations of Ach receptors overstimulation at different regions. OP intoxication can be through inhalation, ingestion, or dermal contact. The severity depends on the quantity of OP intoxicated and the route of intoxication. In $10-40 \%$ of poisoning cases, characteristic neurological features such as neck flexion weakness, decreased deep tendon reflexes, cranial nerve abnormalities, proximal muscle weakness, and respiratory insufficiency occur which are referred to as "Intermediate Syndrome" (IMS) [2]. OP-induced IMS was firstly reported in Sri Lanka in 1987 [3].

\section{CASE REPORT}

A 16-year-old male with a bodyweight of $60 \mathrm{~kg}$ presented to the emergency with an alleged history of consumption of OP

\section{Access this article online}

Received - 20 October 2021

Initial Review - 05 November 2021

Accepted - 19 November 2021

DOI: $10.32677 /$ ijcr.v7i11.3139 compound (Monocrotophos, one of the OP compounds, as indicated on the box presented by the relatives) of an unknown quantity at his residency $4-5 \mathrm{~h}$ before the hospital presentation. As soon as, the patient presented to the emergency department in view of the OP compound odor, the patient was undressed and cleaned with normal saline to mask the smell from the OP compound that fell on the dress and adsorbed on the dermal tissue while intoxication, if any.

At the time of arrival, the patient was drowsy and frothing without a history of vomiting and convulsions. Initial vitals were as follows: Blood pressure 160/100 $\mathrm{mmHg}$; pulse rate 135/min; respiratory rate $24 / \mathrm{min} ; \mathrm{SpO}_{2:} 92 \%$ on 15 liters of $\mathrm{O}_{2}$; and general random blood sugar $200 \mathrm{mg} / \mathrm{dl}$. Physical examination showed bilateral ptosis, pinpoint pupils, neck dropping + , power $0 / 5$ in all the four limbs, OP odor+, and Glasgow Coma Scale 7/15 $\left(\mathrm{E}_{2} \mathrm{~V}_{2} \mathrm{M}_{3}\right)$.

Pathological examination showed serum cholinesterase of $407 \mathrm{U} / \mathrm{mL}$ and blood urea of $124 \mathrm{mg} / \mathrm{dl}$. Initial arterial blood gas $(\mathrm{ABG})$ showed severe mixed acidosis with $\mathrm{pH}$ : 7.255;

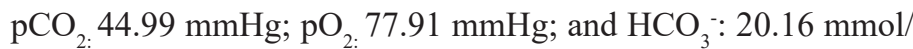
lit. Chest X-ray showed bilateral pneumonia as shown in Fig. 1.

In view of the low saturation and aspiration, the patient was intubated in an emergency, sedated, and paralyzed. Gastric lavage was done with 5 liters of normal saline through Ryle's Tube (Nasogastric tube), given with pralidoxime (PAM) (inj. PAM) $2 \mathrm{~g}$

Correspondence to: Dr. Nithish Sattoju, Plot No. 65, Flat No. 202, Kavuri Hills, Madhapur, Hyderabad, Telangana - 500 018, India. E-mail: nithish.sattoju17@ gmail.com

(C) 2021 Creative Commons Attribution-NonCommercial 4.0 International License (CC BY-NC-ND 4.0). 
Table 1: Clinical presentations of Ach receptors overstimulation at different regions [1]

\begin{tabular}{llll}
\hline & \multicolumn{2}{c}{ Overstimulation of Ach receptors in } \\
\hline Parasympathetic system & Sympathetic system & Central nervous system & Neuromuscular junction \\
\hline Bronchospasm & Tachycardia & Confusion & Muscle weakness \\
Bronchorrhea & Mydriasis & Agitation & Paralysis \\
Miosis & Hypertension & Coma & Fasciculation \\
Lachrymation & Sweating & Respiratory failure & \\
Urination & & & \\
Diarrhea & & \\
Hypotension & & & \\
Bradycardia & & & \\
Vomiting & & & \\
Salivation & & &
\end{tabular}

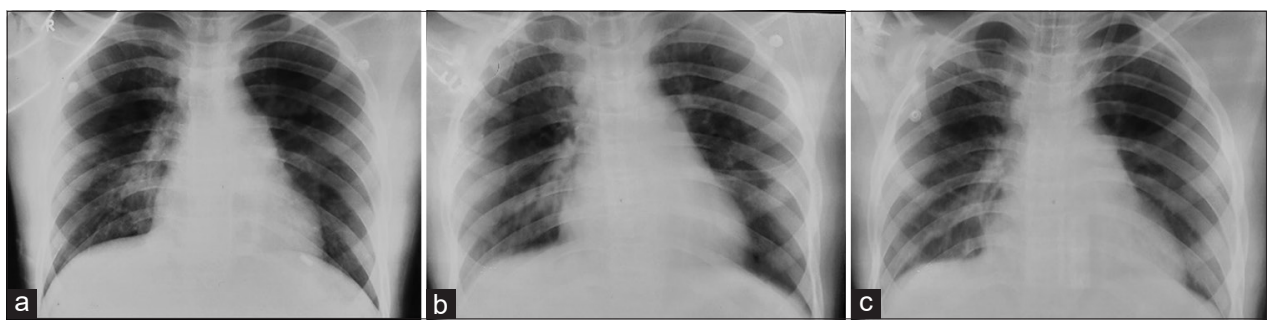

Figure 1: Chest X-ray showing B/L Pneumonia. (a) Chest X-ray on the day of admission with greater bilateral pneumonia. (b) Chest X-ray on $3^{\text {rd }}$ day of hospital stay showing little decrease in the pneumonia. (c) Chest $\mathrm{X}$-ray on $5^{\text {th }}$ day of admission showing almost recovered lungs with minimal pneumonia

iv stat dose, and maintained as $500 \mathrm{mg} / \mathrm{h}$ infusion. Inj. atropine (inj. Tropine) infusion was started as $1 \mathrm{mg} / \mathrm{h}$ when heart rate was $<120 /$ min on the day of admission. Despite of heart rate in the higher range, in view of bronchorrhea, miosis, and increased lung secretions, atropine was continued, escalated to the $2 \mathrm{ml} / \mathrm{h}$ next day, continued till the $3^{\text {rd }}$ day, and then weaned off in view of increased CNS depression and in plan of extubation. The patient was started with glycopyrrolate (Inj. pyrolate) 1 cc, i.v., QID in place of atropine as this has low CNS penetration. ABG after 1 day showed significant improvement with values as $\mathrm{pH}$ : 7.323; $\mathrm{pCO}_{2:} 52 \mathrm{mmHg}$; $\mathrm{pO}_{2:}: 194 \mathrm{mmHg}$; and $\mathrm{HCO}_{3}^{-}: 27 \mathrm{mmol} / \mathrm{lit}$.

The patient presented with fever spikes on the $3^{\text {rd }}$ day after admission which was considered secondary either due to atropine or pneumonia since procalcitonin, blood, and sputum culture sensitivity tested negative. Power in all four limbs was increased from $1 / 5$ on the initial 2 days of admission to $4 / 5$ on the $3^{\text {rd }}$ day and achieved full power $5 / 5$ on the $4^{\text {th }}$ day. Mechanical ventilation was continued for 3 days with positive end-expiratory pressure of six, $\mathrm{FiO}_{2}$ as $50 \%$ on the day of admission, $40 \%$ next day, $30 \%$ on the $3^{\text {rd }}$ day, maintained on T-piece for $24 \mathrm{~h}$ with 5 liters, and then extubated on the $4^{\text {th }}$ day. The post-extubation period was uneventful and the patient was provided with 5-6 $\mathrm{L}_{\text {of }} \mathrm{O}_{2}$ support through face mask for $24 \mathrm{~h}$ which was tapered slowly and taken off $\mathrm{O}_{2}$ support after $24 \mathrm{~h}$. Feeds were given to the patient through Ryle's tube for 4 days and extubated on the $5^{\text {th }}$ day after oral liquid compliance and shifted out from the ICU to the general ward. By the $6^{\text {th }}$ day, the patient was brought to a hemodynamically stable state and discharged from the hospital. At the time of discharge, a 6 min-walk test was negative with pupils normal in size and reactive to light and clear lung fields with no bronchorrhea as seen on the chest X-ray. The course of the patient in the hospital is detailed as an algorithm in Fig. 2.

\section{DISCUSSION}

As per the National Crime Bureau of India report in the year 2007, among all the poisoning cases reported, OP poisoning accounted for $19.7 \%$. In developing agricultural countries such as India, the use of OP is more prevalent and so ingestion of OP incidentally in a suicide attempt is more common. However, besides parenteral ingestion, long-term exposure to the OP while spraying in the agricultural lands may also pose a threat to the farmers leading to OP poisoning [4]. An estimate of $>3$ million people is exposed to OP worldwide every year of which, about 300,000 deaths are being reported. The widely seen reason for deaths in OP toxicity is type 2 respiratory failure secondary to bronchoconstriction, bronchorrhea, central respiratory depression, or paralysis of respiratory muscles [5].

Among various OP compounds, monocrotophos has the highest lethality rate and the need for mechanical ventilation followed by methylparathion [6]. However, methamidophos, dimethoate, and monocrotophos were the most fatal organophosphorus compounds resulting in death on selfintoxication [7]. The chemical formula of monocrotophos is $\mathrm{C}_{7} \mathrm{H}_{14} \mathrm{NO}_{5} \mathrm{P}$ and the IUPAC name is dimethyl (E)-1-methyl2-(methyl carbamoyl) vinyl phosphates [8]. The toxic levels of monocrotophos (OP compound) are as oral LD: $5014 \mathrm{mg}$ / $\mathrm{kg}$ body weight; dermal LD 50: $112 \mathrm{mg} / \mathrm{kg}$ body weight, and accepted daily intake: $0.0006 \mathrm{mg} / \mathrm{kg}$ body weight [9].

The wide use of monocrotophos in agriculture leads to groundwater and surface water contamination causing neuro and genotoxicity of various organisms [10]. However, fatal dermal toxicity of OP is rarely reported [11]. Mortality associated with OP poisoning was $25 \%$ of which, the majority of deaths noted due 


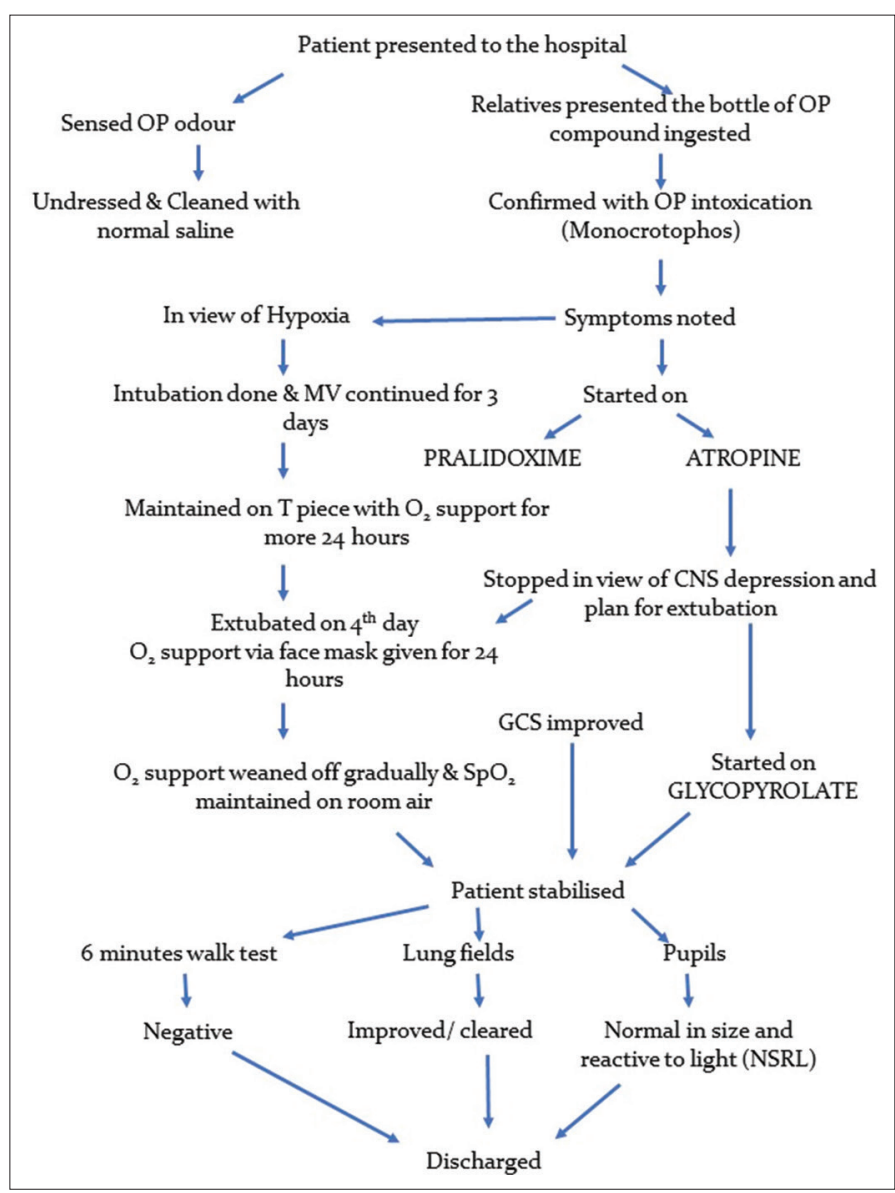

Figure 2: Algorithm of the case study representing the patient hospital course

to delay in discovery and transport of the patient to the hospital and due to respiratory failure [12].

However, early diagnosis and proper intervention with the use of atropine and oximes can be life-saving. The use of oximes (PAM) as a life-saving treatment is not significant since the patients treated alone with atropine were also successfully treated. Management of OP poisoning includes the use of antidotes (PAM and atropine) as suggested by the World Health Organization (WHO). PAM regenerates functional Ach and atropine inhibits the build-up of excess Ach [13]. Atropine is to be given before the administration of PAM to avoid the worsening of muscarinicmediated symptoms. As recommended by the WHO, the dosage of PAM is $30 \mathrm{mg} / \mathrm{Kg}$ for adults and $20-50 \mathrm{mg} / \mathrm{Kg}$ for children should be given as a bolus over $30 \mathrm{~min}$, followed by the infusion of $8 \mathrm{mg} / \mathrm{kg} / \mathrm{h}$ for adults and $10-20 \mathrm{mg} / \mathrm{kg} / \mathrm{h}$ for children should be started and maintained till the neurological improvement is seen $[14,15]$. Atropine should be given as a loading dose of $2-5 \mathrm{mg}$ intravenously for adults and $0.05 \mathrm{mg} / \mathrm{Kg}$ iv for children. Even after 5-10 min of the first dose administration, if pulmonary muscarinic symptoms persist, then double the initial dose administration is advisable [15]. Identification of the type of OP compound intoxicated by the patient plays a key role in the management as few lipid-soluble OP compounds do not present clinically soon after ingestion but may lead to death after a few days, if untreated [16].

\section{CONCLUSION}

As in this case study, the incidental oral ingestion of OP by adolescence was presented with tachycardia and without seizures (non-linear presentation in case of OP poisoning) resulted in hospitalization for 6 days with an initial intubation period of 4 days. However, the management of the patient with atropine, PAM, and mechanical ventilation guarded the prognosis and improved the outcome of the patient.

Informed consent: An informed consent is obtained from the patient's attender for collecting the information and publishing the same by masking the personnel details.

\section{ACKNOWLEDGEMENT}

I take this opportunity to thank Medical Director of Medisys Hospitals, Dr. Chandra Shekar Reddy, M.B.B.S., MRCGP (UK), for allowing us to do this case study report and publish.

\section{REFERENCES}

1. Eddleston M, Buckley NA, Eyer P, Dawson AH. Management of acute organophosphorus pesticide poisoning. Lancet 2008;371:597-607.

2. Narang U, Narang P, Gupta O. Organophosphorus poisoning: A social calamity. J Mahatma Gandhi Inst Med Sci 2015;20:46.

3. Gupta PK. Toxic effects of pesticides and agrochemicals. In: Concepts and Applications in Veterinary Toxicology. Cham: Springer; 2019. p. 59-82.

4. Narang U, Narang P, Gupta O. Organophosphorus poisoning: A social calamity. J Mahatma Gandhi Inst Med Sci 2015;20:46.

5. Robb EL, Baker MB. Organophosphate Toxicity. Treasure Island, FL: StatPearls Publishing; 2021.

6. Lockridge O. Noncholinesterase protein targets of organophosphorus pesticides. In: Advances in Molecular Toxicology. Vol. 7. Amsterdam, Netherlands: Elsevier; 2013. p. 179-205.

7. Caldas ED. Pesticide poisoning in Brazil. Reference Module in Earth Systems and Environmental Sciences. Amsterdam, Netherlands: Elsevier; 2016.

8. Monocrotophos; 2021. Available from: http://www.pic.int/portals/5/dgds/ dgd_monocrotophos_en.pdf [Last accessed on 2021 Oct 24].

9. Guidelines for Computing Crop Water Requirements-FAO Irrigation and Drainage Paper No. 56; 2021. Available from: https://www.fao.org/3/ w5715e/w5715e 04.htm [Last accessed on 2021 Oct 12].

11. Kaur R, Goyal D. Toxicity and degradation of the insecticide monocrotophos. Environ Chem Lett 2019;17:1299-324.

12. Bodwal J, Chauhan M, Behera C, Jitendra K. Fatal monocrotophos poisoning by cutaneous absorption while sleeping: A remarkable case study. Med Legal J 2019;87:144-50.

13. Walton EL. Pralidoxime and pesticide poisoning: A question of severity? Biomed J 2016;39:373-5.

14. Robb EL, Baker MB. Organophosphate Toxicity. Treasure Island, FL: StatPearls Publishing; 2021.

15. Adeyinka A, Kondamudi NP. Cholinergic Crisis. Treasure Island, FL: StatPearls Publishing; 2021.

16. Davies JO, Eddleston M, Buckley NA. Predicting outcome in acute organophosphorus poisoning with a poison severity score or the Glasgow coma scale. QJM 2008;101:371-9.

Funding: None; Conflicts of Interest: None Stated.

How to cite this article: Nithish S, Prasad JS, Sujala A, Kumar EJ. Management of self-inflicted oral organophosphate poisoning in adolescence-a case report. Indian J Case Reports. 2021;7(11):500-502. 